\title{
Alkol Yakıtların Buji Ateşlemeli Motorlarda Kullanımının Performans ve Emisyonlara Etkisinin İncelenmesi
}

\author{
Ali Şenbahçe ${ }^{1}$, Mustafa Temür ${ }^{2}$, Cenk SAYIN $^{3}$ \\ ${ }^{1,2,3}$ Marmara Üniversitesi, Teknoloji Fakültesi, Makine Mühendisliği Bölümü, Göztepe Kampüsü,34722, \\ Istanbul, Türkiye
}

\section{Özet}

İçten yanmalı motorlarda yakıt tüketimi, hava kirliliği ve çevre koşulları açısından benzine alternatif oluşturabilecek yeni ve yenilebilir enerji kaynakların önemi oldukça artmaktadır. $\mathrm{Bu}$ çalışmada, benzin ve metanol-benzin (M5, M10, M20 ve M50) karışımlarının, motor performansı ve egzoz emisyonlarına etkisi deneysel olarak incelenmiştir. Deneyler, dört zamanlı, tek silindirli, buji ile ateşlemeli bir motorda ve motor dinamometresi kullanılarak 10 $\mathrm{Nm}$ ve $20 \mathrm{Nm}$ motor yükünde ve 2000 d/d'da sabit hızda yapılmıştır. Deneyler sonucunda, karışımdaki metanol oranının artmasıyla özgül yakıt tüketimi artarken, efektif verim, $\mathrm{NO}_{\mathrm{x}}$, $\mathrm{HC}, \mathrm{CO}_{2}$ ve $\mathrm{CO}$ emisyonları azalmaktadır.

\section{The Effect of Using Alcohol Fuels on the Performance and Emissions in Spark Ignition Engines}

\begin{abstract}
In internal combustion engines, the importance of new and renewable energy resources which may be an alternative to gasoline in terms of fuel consumption, air pollution and environmental conditions notably increases. In this study, the effect of gasoline and methanol-gasoline (M5, M10, M20 and M50) mixtures on the engine performance and exhaust emissions has been experimentally examined. The experiments have been performed on a four-stroke, single cylinder and spark plug ignition engine by using engine dynamometer at $10 \mathrm{Nm}$ and $20 \mathrm{Nm}$ engine load and at $2000 \mathrm{rev} / \mathrm{min}$ constant speed.In consequence of experiments, effective output, $\mathrm{NOx}, \mathrm{HC}, \mathrm{CO} 2$ and $\mathrm{CO}$ emissions decrease while specific fuel consumption increases with the increase of methanol ratio in the mixture.
\end{abstract}

Keywords: Alcohol Fuels, Methanol, Engine Performance, Exhaust Emissions

Sorumlu yazar/Corresponding author: Cenk SAYIN Tel: 0216-336-57-70/1318, e-posta: csayin@marmara.edu.tr 


\section{Giriş}

Dünyada sanayileşme ve artan nüfus nedeniyle enerji ihtiyacı günden güne artmaktadır. Bunun sonucunda da tüm dünyada enerji açığı ortaya çıkmaktadır. Sanayileşmiş ve sanayileşmekte olan ülkeler enerji ihtiyaçlarını karşılamak için yeni enerji kaynaklarına yönelmektedir. Yeni ve yenilebilir enerji kaynaklarının geliştirilmek istenmesinin bir başka sebebi de, dünyadaki fosil yakıt rezervlerinin tükeniyor olmasıdır. Üretilebilir petrol ve doğal gaz rezervlerinin azalması, insanlığın geleceği açısından düşündürücüdür. Günümüzde kullanılan motorlu taşıtların egzoz gazlarının sebep olduğu hava kirliliğinin, önlemler alınmasını gerektiren bir çevre sorunu haline gelmesi, kullanılan enerji kaynaklarının ekonomik kriz sebebiyle ekonomiklik özelliklerini yitirmesi ve bu kaynakların zamanla tükenecek olması bilim adamlarını bu enerji kaynaklarının yerine alternatif enerji kaynaklarını araştırmaya yöneltmiştir. İçten yanmalı motorlarda (IYYM)'de kullanılan yakıtın kolayca buharlaşabilmesi, birim hacminden yüksek enerji sağlanabilmesi ve dünyanın her yerinde kolay bulunabilmesi istenir. Araştırmacılar, motorlar üzerinde yaptıkları çalışmalarda, yüksek verimli ve çevreci motorların geliştirilmesini hedeflemişlerdir. Fosil kökenli yakıtlar, yakıtın özelliklerinden dolayı motor performansını sınırlayıcı nedenler, yenilebilir alternatif yakıtların araştırılmasını zorunlu duruma getirmiştir. 1976 yılından beri etanol ve metanol gibi alkol kökenli yakıtların IYYM'de kullanılması ile ilgili çalışmalar artarak devam etmektedir [1-2].

Günümüzde bazı alkol yakıtlar (etanol, metanol gibi) bitkisel kaynaklardan da üretilmektedir. Üretilmesi fiziksel ve kimyasal işlemler sonucu oluşur. Ülkemizde tarımsal alanları göz önünde bulundurursak, bitkisel kökenli yakıt üretimi de buna paralel olarak önem kazanmaktadır. Bununla beraber, ülkemizde de kimyasal olarak, etanol ve metanol üretimi de yapılmaktadır. Alkol yakitlar Buji Ateşlemeli Motorlar (BAM)'da yakıt olarak kullanıldıklarında benzine oranla bazı avantajlar sağlamaktadır. Metanolün vuruntu direnci benzine göre daha yüksektir. SO'nun fazlalaştırılmasıyla efektif verim $(\eta)$ iyileştirilebilir [4-5]. Metanol BAM'da saf olarak veya benzin ile karıştırılarak kullanılabilmektedir. Saf olarak kullanılırsa, motor ve yakıt sisteminde bazı değişikler yapmak gerekirken, karışım olarak kullanıldığında herhangi bir değişiklik yapmaya gerek olmadan kullanılabilir. Bu iki yöntemde de performans ve emisyonlarda önemli iyileşmeler olmaktadır [3].

Metanolün $\mathrm{H} / \mathrm{Y}$ oranının düşük olması yakıtın kimyasal bileşiminde bulunan oksijen neden olmaktadır. Metanol içerisindeki oksijen oranı kütlesel olarak \%49,94'dür. Yakıtların alt 1sıl değerleri mukayese edildiğinde benzinin alt 1sıl değerinin metanole göre, 2,204 kat daha fazla olduğu anlaşılmıştır. Bu durum metanol yakıtlı çalışmalarda birim güç başına benzine oranla daha fazla yakıt harcamasına neden olmaktadır. Stokiyometrik H/Y oranının az olması karışımın 1sıl değerini artırmaktadır. Bunun için, metanolün BAM'larda kullanılması teorik olarak, ısıl değer bakımından bir kayıp değildir. Ancak, birim güç başına tüketilen yakıt miktarının benzine oranla oldukça fazla olması kaçınılmazdır.

Literatürde metanolün BAM'larda saf olarak ya da karışım olarak uygulanmasına yönelik birçok çalışma bulunmaktadır. Abu-Zaid vd. yapmış oldukları çalışmada benzine metanol ilavesi ile buji ateşlemeli bir motorun performansını incelemişlerdir. Performans testleri tam gaz kelebeği açıklığında, $1000-2500 \mathrm{~d} / \mathrm{d}$ aralığında ve değişik yüklerde gerçekleştirilmiştir. Testler sonucunda metanol-benzin karışımı kullanılan yakıtın motor performansı üzerinde önemli bir etkiye sahip olduğu bulunmuştur. En iyi performansın \%15 metanol-\%85 benzin karışımında olduğu tespit edilmiştir [4].

Al-Dawood yapmış olduğu deneysel çalışmada buji ateşlemeli bir motorda, metanol ve etanol yakıtlarını benzin ile üç değişik oranda (hacimsel olarak \%10, 15 ve 20) karıştırarak motor yakıtı olarak kullanılmışır. Bu yakıtların kullanılmasının motor performansı ve egzoz emisyonlarına olan etkileri incelenmiştir. Test sonuçlarına göre oksijenli yakıtlardan elde edilen ISV (Isıl verim)'nin kurşunlu benzine göre daha iyi olduğu görülmüştür. Metanol karışımlı yakıttan elde edilen ISV ve motor gücünün diğer oksijenli yakıtlara göre daha iyi olduğu tespit edilmiştir [5].

Bilgin ve Sezer buji ateşlemeli bir motorun metanol-benzin karışımları kullanılarak motor performansı ve yakıt maliyetleri baz alınarak yapmış oldukları testlerde, yakıt karışımları olarak \%5, \%10, \%15 ve $\% 20$ metanol-benzin yakıtlarını kullanmışlardır. Fren termik veriminin (BTE)'nin ise en iyi performansının \%20 metanol-benzin karışımında olduğu tespit edilmiştir. \%5, \%10, \%15 ve \%20 
metanol-benzin karışımlarının benzine göre maliyet artışlarının sırasıyla \%18.86, \%36.95, \%54.20 ve \%73.01 olduğu hesaplanmıştır [6].

Çanakçı vd. dört silindirli ve dört zamanlı bir benzin motorunda etanol-benzin ve metanol-benzin karışımlarının motor performansı ve egzoz emisyonlarına etkisini incelemişlerdir. Deneyler dört farklı karışım oranında (\%5 metanol-\%95 benzin, $\% 10$ metanol- $\% 90$ benzin, $\% 5$ etanol- $\% 95$ benzin ve $\% 10$ etanol- \%90 benzin), dört farklı motor yükünde $(5,10,15,20 \mathrm{~kW})$ ve iki farklı taşı hızında gerçekleştirilmiştir. Elde edilen verilere göre; karışım içerisindeki alkol miktarının artışıyla CO, $\mathrm{HC}$, $\mathrm{NO}_{\mathrm{x}}$ ve $\mathrm{CO}_{2}$ emisyonunda azalma ÖYT'de ise artma gözlenmiştir [7]. Literatür incelendiğinde farklı oranlardaki metanol-benzin karışımları kullanımında emisyon, performans ve yanma özelliklerinin etkisinin bir bütünlük içerisinde araştırılmadığı görülmektedir. Bu çalışma ile bu eksikliğin giderilmesi amaçlanmıştır.

\section{Deneysel Çalışma}

Deney donanımında; tek silindirli benzinli motor, elektrikli (eddy current) dinamometre, egzoz gaz analizörü, hava ve yakıt tüketimi ölçüm düzeneğinden oluşmaktadır. Deneyler, Marmara Üniversitesi, Teknoloji Fakültesi, Makine Mühendisliği Bölümü, Otomotiv laboratuvarında gerçekleştirilmiştir. Test donanımının şematik ve genel görünümü Şekil 2.1 ve Şekil 2.2'de verilmiştir. Testlerde KIPOR AG390 marka tek silindirli bir test motoru kullanılmıştır. Şekil 1. Deney motoruna ait teknik özellikler Tablo 1'de görülmektedir. Deneylerde saf olarak kurşunsuz benzin ve metanol yakıtları kullanılmıştır. MERCK ticari firmasından temin edilen metanol yakıtı \%99,9 saflık derecesindedir. Testlerde kullanılan yakıtlarının bazı fiziksel ve kimyasal özellikleri Tablo 2'de gösterilmiştir

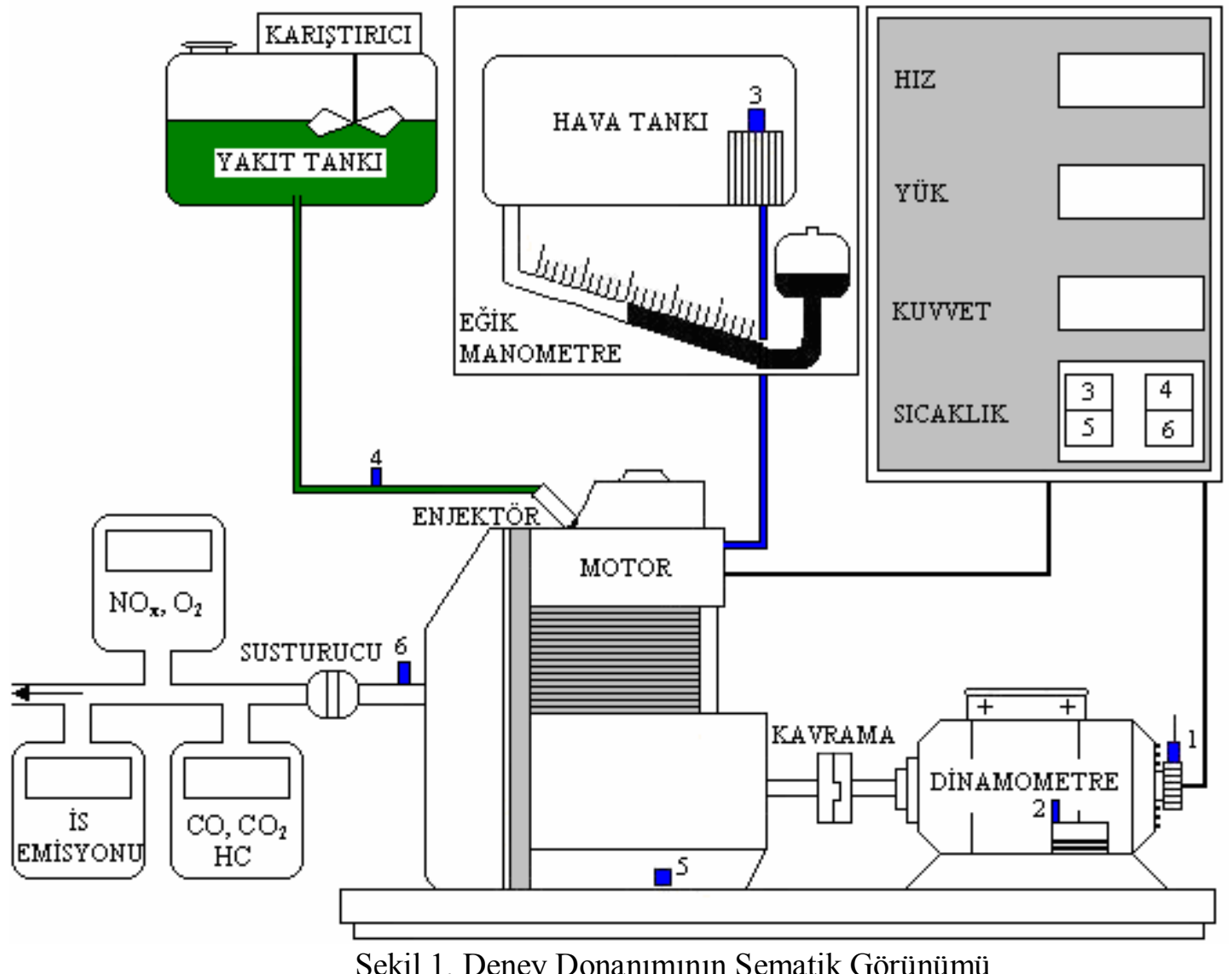

1- Hiz Sensörü 2-Yük Hücresi
5- Yağ Sicaklık Termokuplu
3- Hava Sicaklık Termokuplu 4- Yakıt Sicaklık Termokuplu 6- Egzoz Sicaklık Termokuplu 
Tablo 1. Deney motoruna ait teknik özellikler

\begin{tabular}{ll}
\hline Özellikler & \\
\hline Motor tipi & Hava soğutmalı, 4-zamanlı, \\
Maksimum motor momenti & $16 \mathrm{Nm} / 2200 \mathrm{~d} / \mathrm{d}$ \\
Silindir çapı x kurs & $88 \times 64 \mathrm{~mm}$ \\
Motor hacmi & $389 \mathrm{cc}$ \\
SO & $8: 1$ \\
Net çıkış gücü & $4,8 \mathrm{~kW} / 3600 \mathrm{~d} / \mathrm{d}$ \\
Yağ türü & $15 / 40$ \\
Yă̆ kapasitesi & 1,11 \\
Motor ağırlığı & $35 \mathrm{~kg}$ \\
\hline
\end{tabular}

Tablo 2. Deney yakıtların bazı fiziki ve kimyasal özellikleri [8].

\begin{tabular}{|c|c|c|c|}
\hline & Birim & Saf Benzin & Metanol \\
\hline Kimyasal formülü & & - & $\mathrm{CH}_{3} \mathrm{OH}$ \\
\hline Molar ağırlı̆̆g & $\mathrm{g} / \mathrm{mol}$ & $95-120$ & 32,04 \\
\hline Tutuşma sıcaklığı & ${ }^{\circ} \mathrm{C}$ & 210 & 455 \\
\hline Yoğunluk $\left(20^{\circ} \mathrm{C}\right)$ & $\mathrm{kg} / \mathrm{m}^{3}$ & $720-775$ & 792 \\
\hline $\begin{array}{l}\text { Kaynama noktasi }(101,3 \\
\text { kPa) }\end{array}$ & ${ }^{\circ} \mathrm{C}$ & $27-225$ & 64,5 \\
\hline Buhar basıncı $\left(20^{\circ} \mathrm{C}\right)$ & $\mathrm{kPa}$ & $45-90$ & 12,8 \\
\hline Yanma limitleri & $\%$ hacim & $1,4-7,6$ & $5,5-36,5$ \\
\hline Alevlenme noktası & ${ }^{\circ} \mathrm{C}$ & 25 & 11 \\
\hline Alt ısıl değer & $\mathrm{kJ} / \mathrm{kg}$ & 44300 & 20100 \\
\hline
\end{tabular}

Deneylerde kullanılan metanol-benzin karışımları aşağıdaki gibidir.
M0 : \%100 Benzin M5 : \%5 Metanol + \%95 Benzin $\quad$ M10 : \%10 Metanol + \%90 Benzin M20 : \%20 Metanol + \%80 Benzin M50 : \%50 Metanol + \%50 Benzin

Egzoz emisyonlarının ölçümü için Bilsa Mod 2000 (G486) egzoz emisyon analiz cihazı kullanılmıştır, Egzoz gaz analiz cihazının teknik özelikleri Tablo 3' de verilmiş̧ir. Egzoz gaz analiz cihazı ile $\mathrm{NO}_{\mathrm{x}}$, $\mathrm{HC}, \mathrm{CO}, \mathrm{CO}_{2}, \lambda$ ve $\mathrm{O}_{2}$ değiş̧kenleri ölçülebilmektedir.

Tablo 3. Egzoz gaz analiz cihazının teknik özelikleri

\begin{tabular}{lll}
\hline Parametreler & Ölçüm Aralıkları & Hassasiyeti \\
\hline$(\mathrm{CO})$ & $(\mathrm{CO}) 0 \ldots 12 \%$ Vol & $\% 0,001$ \\
$(\mathrm{CO} 2)$ & $0 \ldots .25 \% \mathrm{Vol}$ & $\% 0,01$ \\
$(\mathrm{HC})$ & $(0 \ldots .2000 \mathrm{ppm}$ Vol & $1 \mathrm{ppm}$ \\
$\mathrm{NO}_{\mathrm{x}}$ & $0 \ldots .2000 \mathrm{ppm} \mathrm{Vol}$ & $1 \mathrm{ppm}$ \\
\hline
\end{tabular}


Motor testleri $2000 \mathrm{~d} / \mathrm{d}$ sabit hız ve iki farklı (10 ve $20 \mathrm{Nm}$ ) yükte gerçekleştirilmiştir. Deneylere başlamadan önce motor yağ sıcaklığı $65^{\circ} \mathrm{C}$ 'ye gelene kadar çalıştırılmış ve bu sıcaklıktan sonra deneylere başlanmıştır. Test ölçümlerinin kararlılığı açısından, her deneyden sonra motor bir süre dinlenmeye bırakılmıştır. $2000 \mathrm{~d} / \mathrm{d}$ motor hızında, $10 \mathrm{Nm}$ ve $20 \mathrm{Nm}$ yüklerinde, M10, M20 ve M50 yakıtları kullanılarak yapılan deneylerde ÖYT, Egzoz gazı sıcaklığı (EGS), $\mathrm{CO}, \mathrm{CO}_{2}, \mathrm{NO}_{\mathrm{x}}$ ve $\mathrm{HC}$ emisyonları incelenerek, karşılaştırma yapılmıştır.

\section{Bulgular ve Tartışma}

\section{1.Özgül yakıt tüketimi}

ÖYT, birim güç başına birim zamanda tüketilen yakıt miktarıdır. Şekil 2. incelendiğinde, motor yükü arttıkça ÖYT azalmaktadır. $10 \mathrm{Nm}$ yükte M10 yakıtı için ÖYT değeri 166,34 g/kWh iken 20 Nm'de yine aynı yakıt için $116,88 \mathrm{~g} / \mathrm{kWh}$ olarak hesaplanmıştır. Motorun belli çalışma şartlarında emdiği gerçek hava miktarının, teorik hava miktarına oranına volümetrik verim denir. Motor yükünün artmasıyla beraber yanma ürünlerinin egzoz sisteminde kalma süresi azalmaktadır. Sonuç olarak, emme zamanında silindirlere daha fazla hava alınması ile birlikte volümetrik verim artar. Volümetrik verimin artması da ÖYT'nin azalmasina sebep olur [9].

En düşük ÖYT, ve 20 Nm'de M0 yakıtından elde edilmiştir. M5, M10, M20 ve M50 yakıtlarında ÖYT'nin benzine göre ortalama artış miktarları sırasıyla \%12,02; \%21,71; \%31,41 ve \%43,05 olarak belirlenmiştir. Metanol-benzin karışımlarında meydana gelen ÖYT artışının temel nedeni, metanolun içeriğinde oksijen bulundurması sonucunda ısıl değerlerinin benzine göre daha düşük olmasıdır [10].

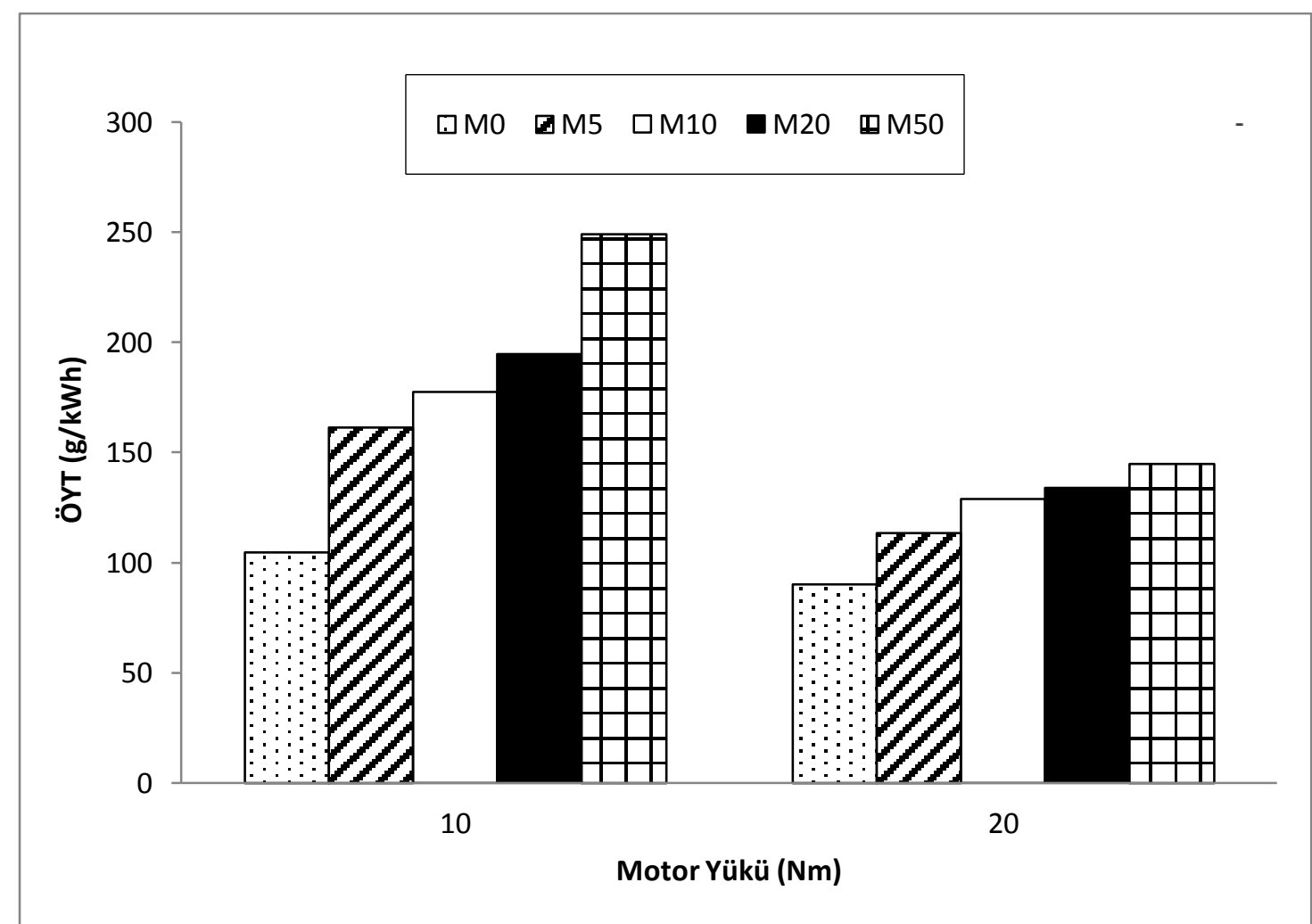

Şekil 2 Motor Yüküne Bağlı Olarak Farklı Karışım Yakıtları İçin Özgül Yakıt Tüketiminin Değişimi.

\subsection{Efektif verim}

Efektif verim $(\eta)$, motor milinden alınan işin, motora verilen toplam enerjiye oranı olarak tanımlanmaktadır. Şekil 3. incelendiğinde, motor yükü arttıkça $\eta$ artmaktadır. $10 \mathrm{Nm}$ yükte M10 yakıtı için $\eta$ değeri \%14,35 iken 20 Nm'de yine aynı yakıt için \%20,43 olarak görülmektedir. Denklem 2.6'da görüldüğü gibi $\eta$ değeri, ÖYT değeri ve karışımın Hu değerinin artması ile beraber azalmaktadır. Motor yükünün artması ile ÖYT azalmaktadır. Bununla beraber $\eta$ değeri artmaktadır [59].En düşük $\eta, 10$ Nm'de M50 yakıtından elde edilmiştir. M5, M10, M20 ve M50 yakıtlarında ๆ'nün 
benzine göre ortalama azalma miktarı sirasıyla \%33,66; \%35,42; \%25,60 ve\%39,29 olarak belirlenmiştir. Metanolün benzine göre adyabatik alev sıcaklıklarının daha düşük olması ve yanma hızlarının yüksek olması ๆ'nün artışında önemli bir neden olmaktadır [11].

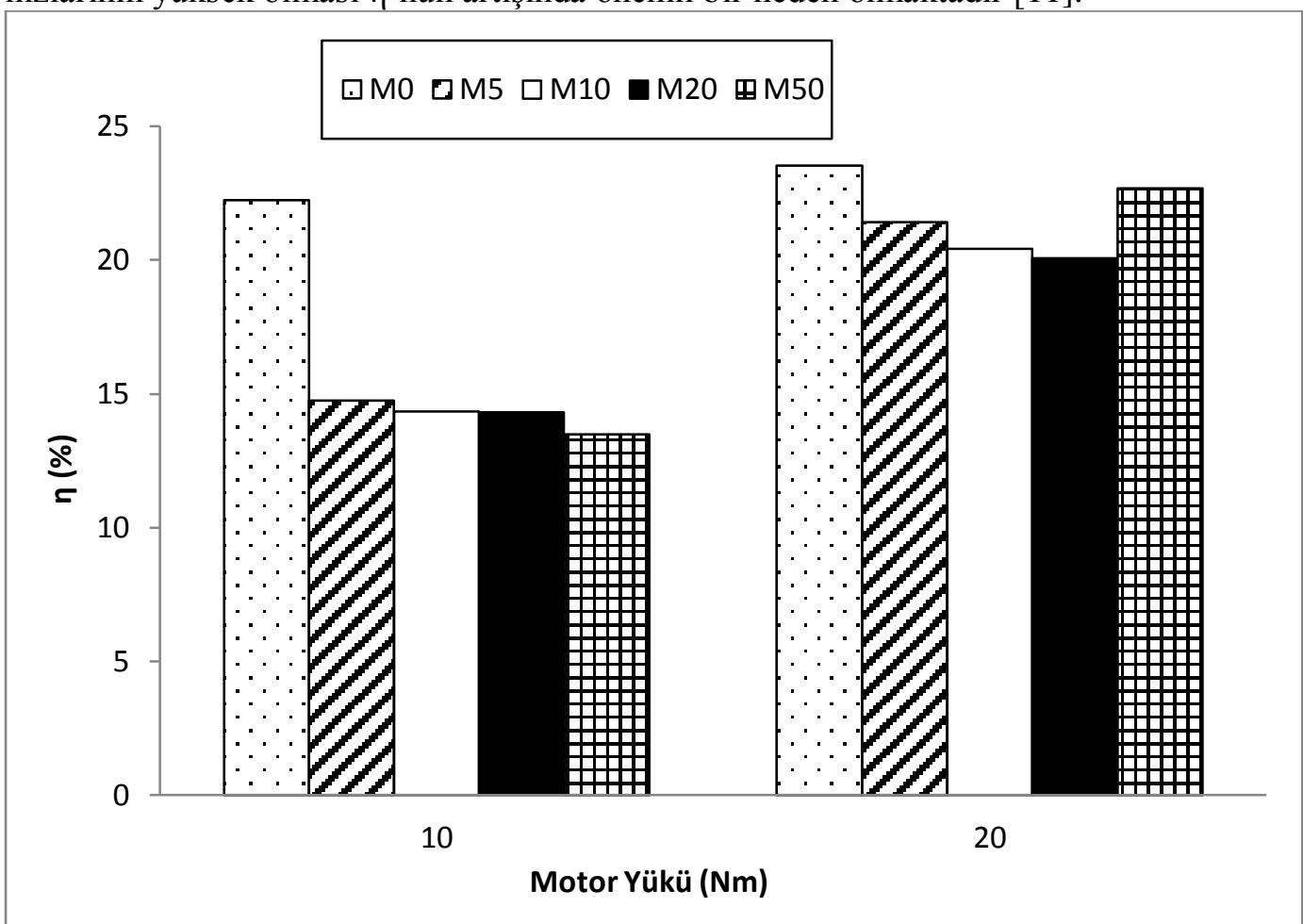

Şekil 3. Motor Yüküne Bağlı Olarak Farklı Karışım Yakıtları İçin Efektif Verim’in Değişimi

\subsection{NOx emisyonu}

$\mathrm{NO}_{\mathrm{x}}$ hava içerisindeki azot $(\mathrm{N})$ atomunun yüksek sıcaklık etkisi ile oksitlenmesi sonucu oluşan bir emisyondur. Şekil 4. incelendiğinde motor yükü arttıkça $\mathrm{NO}_{x}$ azalmaktadır. $10 \mathrm{Nm}$ yükte M10 yakıtı için $\mathrm{NO}_{\mathrm{x}}$ değeri $645 \mathrm{ppm}$ iken $20 \mathrm{Nm}$ 'de yine aynı yakıt için $739 \mathrm{ppm}$ olarak ölçülmüştür. $\mathrm{NO}_{\mathrm{x}}$ oluşumunu silindir içi basınç ve sıcaklığın etkilediği, sıcaklık arttıkça $\mathrm{NO}_{\mathrm{x}}$ emisyonunun da hızla artması beklenir [61]. En düşük $\mathrm{NO}_{\mathrm{x}} 10 \mathrm{Nm}$ 'de M50 yakıtından elde edilmiştir. M5,M10, M20 ve M50 yakıtlarında NOx'in benzine göre ortalama azalma miktarları sırasıla \%2,83; \%7,20; \%11,80 ve $\% 20,29$ olarak belirlenmiştir. Metanolün adyabatik alev sıcaklığının düşük olması $\mathrm{NO}_{\mathrm{x}}$ emisyonlarının azalmasina neden olmaktadır [12-13].

150 ppm iken $20 \mathrm{Nm}$ yükte yine aynı yakıt için 162 ppm olarak ölçülmüştür. Motor yükünün artması ile birlikte karışımın zenginleşmesinden dolayı HC emisyonları artmaktadır [13]. 


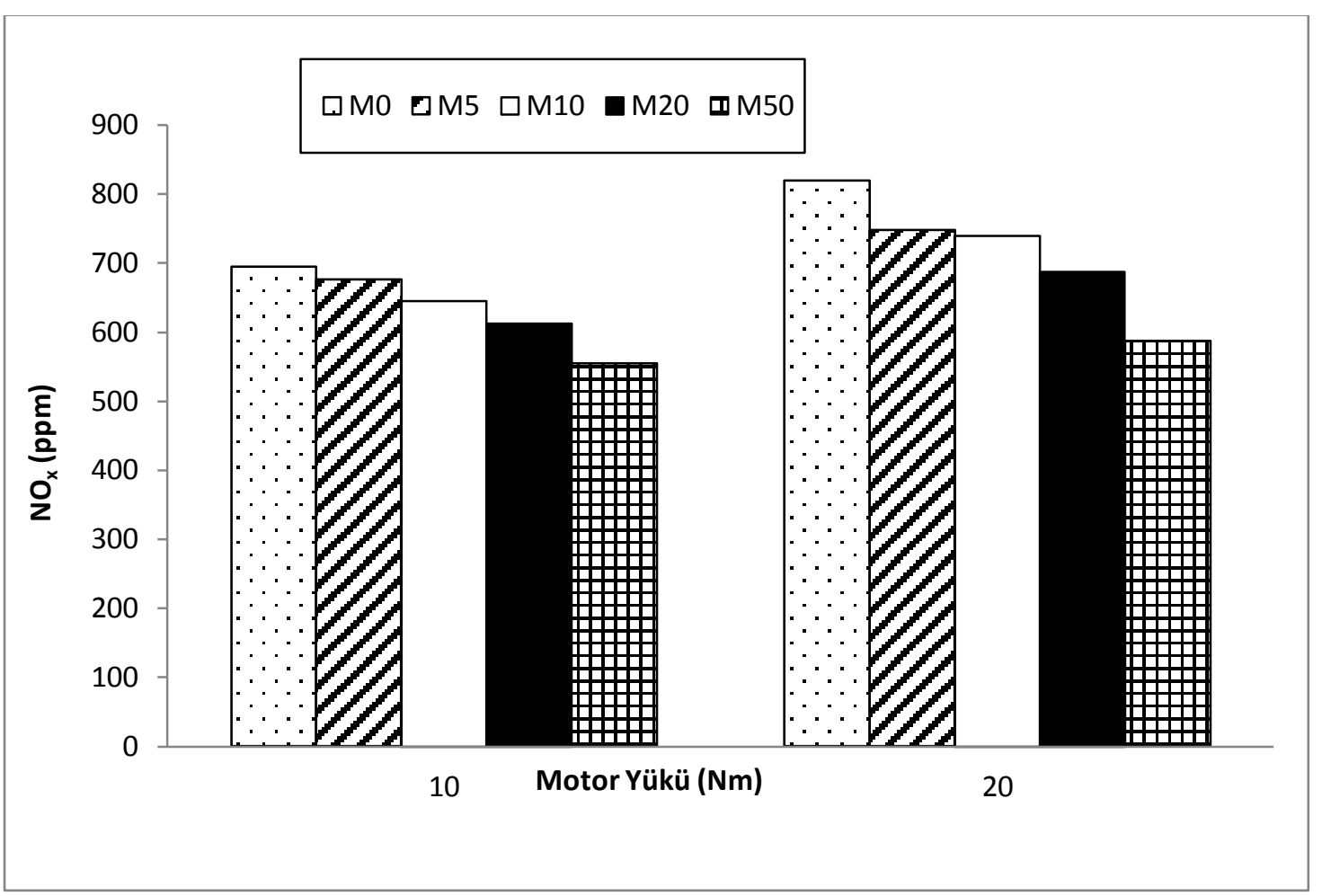

Şekil 4. Motor Yüküne Bağlı Olarak Farklı Karışım Yakıtları İçin $\mathrm{NO}_{\mathrm{x}}$ Emisyonunun Değişimi

\subsection{Yanmamış Toplam HC Emisyonu}

Toplam HC emisyonları yanmamış veya kısmi yanmış hidrokarbon yakıtlardan oluşmaktadır. HC emisyonlarının oluşmasına sebep olan başlıca nedenler fazla zengin veya fakir karışımlar sonucunda oluşan eksik yanma, hava-yakıt karışımı içerisinde bulunan yüksek oranda yanmış egzoz gazları, yanma yüzeylerinde oluşan alev sönmesi, yanma odasındaki karbon birikintileri ve silindir cidarındaki yağ tabakasının yakıt tutması olarak sıralanabilir [12]. Şekil 5. incelendiğinde, motor yükü arttıkça HC emisyonları artmaktadır. M10 yakıtı için HC emisyon değeri150 ppm iken $20 \mathrm{Nm}$ yükte yine aynı yakıt için 162 ppm olarak ölçülmüştür. Motor yükünün artması ile birlikte karışımın zenginleşmesinden dolayı $\mathrm{HC}$ emisyonları artmaktadır [13]. En düşük $\mathrm{HC}$ emisyonu, $10 \mathrm{Nm}$ 'de M50 yakıtından elde edilmiştir. M5, M10, M20 ve M50 yakıtlarında HC'nin benzine göre azalma miktarları sırasıyla \%2,33; \%12,79; \%17,91; \%43,03 olarak belirlenmiştir. HC emisyonlarındaki azalmanın nedeni, metanol içindeki $\mathrm{C}$ miktarının düşük olması ve yapısında $\mathrm{O}_{2}$ bulundurması ile yanma kalitesinin iyileşmesinden kaynaklanmaktadır [14]. 


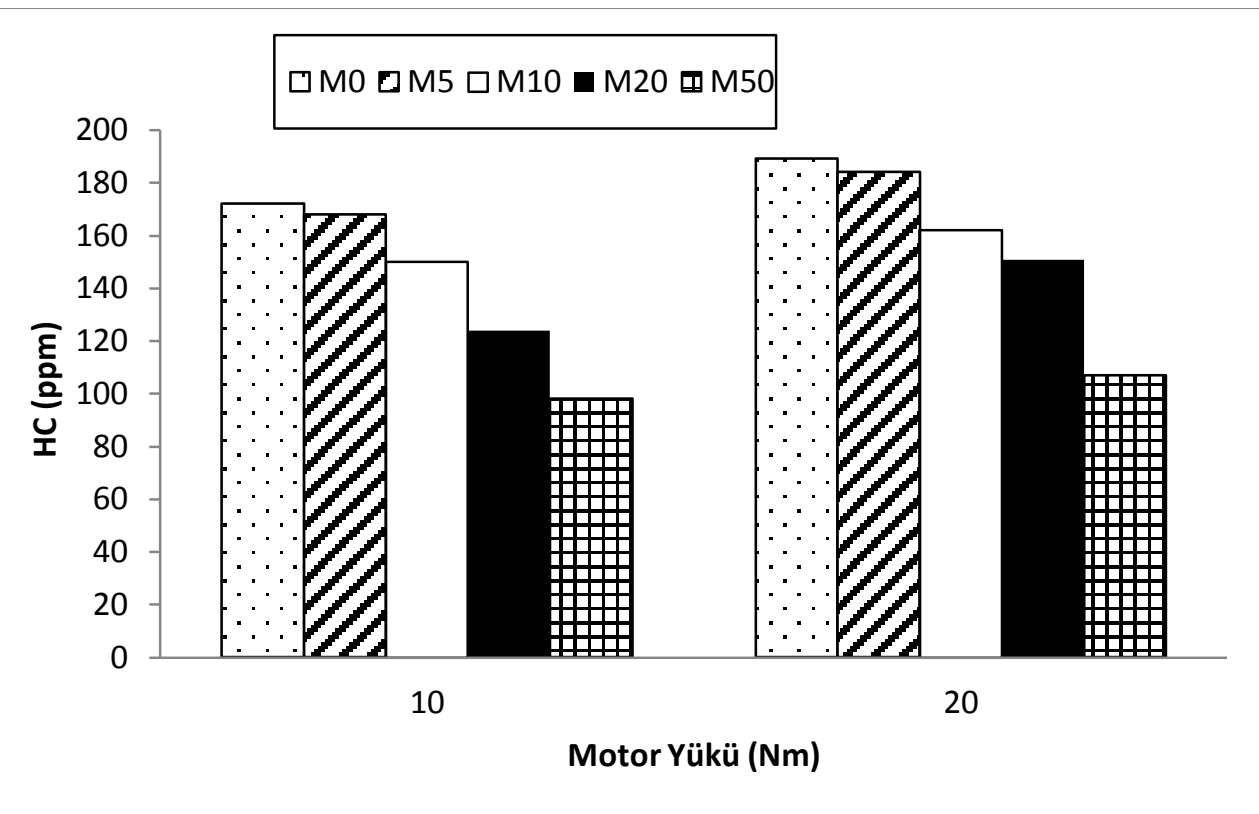

Şekil 5. Motor Yüküne Bağlı Olarak Farklı Karışım Yakıtları İçin HC Emisyonunun Değişimi

\subsection{CO emisyonu}

$\mathrm{CO}$ emisyonu, yanma odası içerisinde yetersiz $\mathrm{O}_{2}$ bulunmasıyla yakıt içerisindeki $\mathrm{C}$ atomlarının tam olarak yanamamasıyla oluşur. CO emisyonu yakıtın kimyasal bileşiminde bulunan $\mathrm{C}$ atomu sayısı ile de ilişkilidir [15-16]. Şekil 6. incelendiğinde, motor yükü arttıkça CO emisyonu artmaktadır. $10 \mathrm{Nm}$ yükte M10 yakıtı için CO değeri \%0,856 iken 20Nm'de yine aynı yakıt için \%0,912 olarak ölçülmüştür. $\mathrm{CO}$ emisyonunu etkileyen başlıca etkenler, $\lambda$, yanma odasındaki türbülans ve yakıtın moleküler yapılarıdır. Eğer $\lambda<1$ ise, yani gerekenden daha az hava var ise yanma yetersiz $\mathrm{O}_{2}$ ortamında olacak ve yakıttaki C'nun tümü $\mathrm{CO}_{2}$ 'ye dönüşmesi gerçekleşmeyerek $\mathrm{CO}$ olarak kalacaktır. Motorda silindir içindeki $\mathrm{O}_{2}$ genel olarak yetersiz olabileceği gibi, karışımın tam homojen olmaması durumunda silindir içinde de yetersiz olabilir [12].

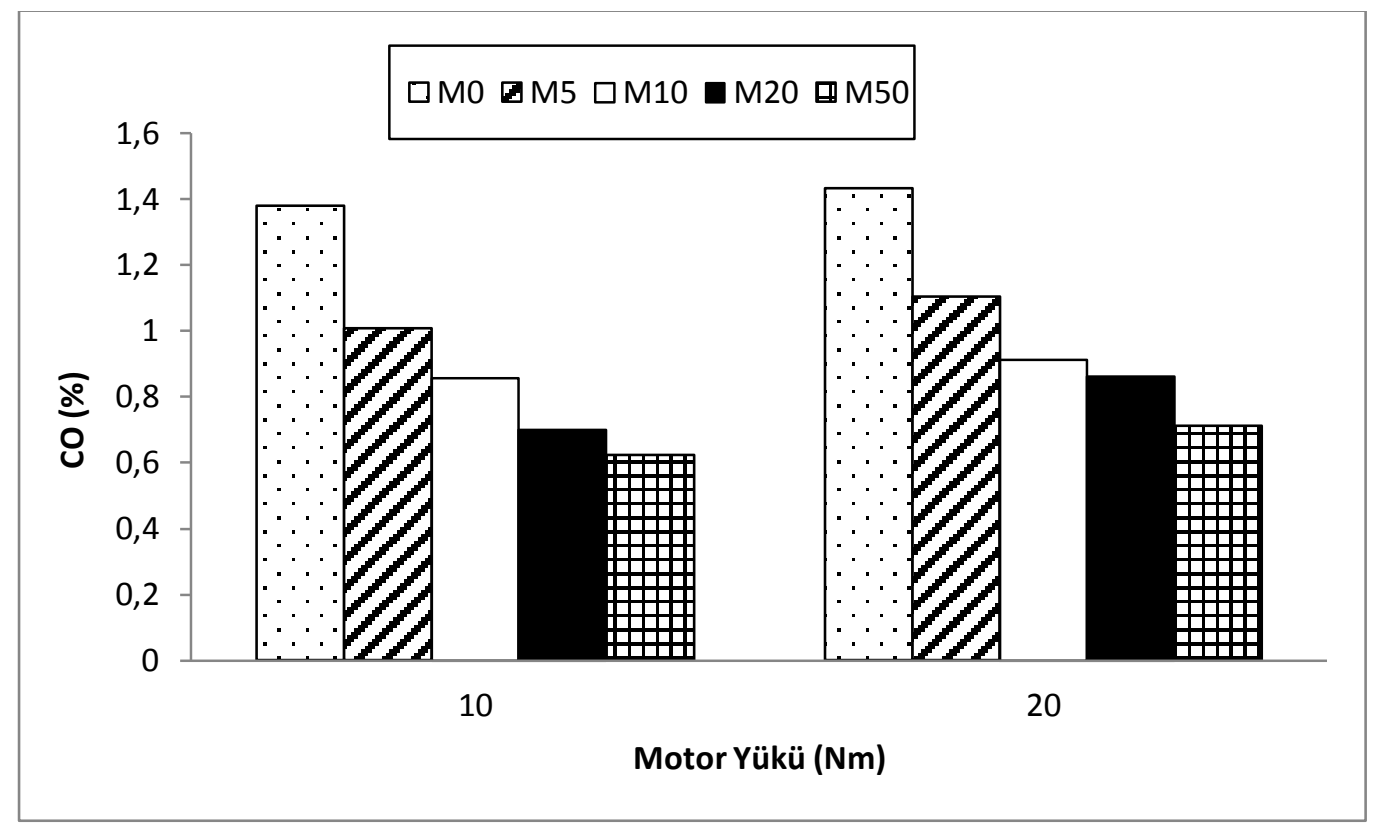

Şekil 6. Motor Yüküne Bağlı Olarak Farklı Karışım Yakıtları İçin CO Emisyonunun Değişimi

En düşük CO emisyonu 10 Nm'de M50 yakıtından elde edilmiştir. M5, M10, M20 ve M50 yakıtlarında $\mathrm{CO}$ emisyonunun benzine göre azalma miktarları sırasıyla $\% 26,92 ; \% 37,89 ; \% 49,13$ ve 
\%55,79 olarak belirlenmiştir. CO emisyonunun azalmasının sebebi, metanolün benzin yakıtına göre daha az C'dan oluşması ve yapısında $\mathrm{O}_{2}$ bulundurmasıdır. Silindir içerisindeki yakıt enjeksiyonunun zengin olduğu bölgelerde metanolün yapısındaki $\mathrm{O}_{2}$ ve $\mathrm{O}_{2}$ /yakıt oranını artırarak yanmanın tam olarak gerçekleşmesi sağlanmaktadır [17-18].

\section{Sonuç}

İçten yanmalı motorlarda, yakıt tüketimi ve egzoz emisyonlarını minimum düzeye indirme çabaları ve özellikle dünyadaki fosil yakıt rezervlerinin tükeniyor olması alternatif yakıtlar üzerine yapılan çalışmaların başlangıç noktasını oluşturur. Bu çalışmada, tek silindirli bir benzin motorunda, çok fazla değişiklikler yapılmadan, $2000 \mathrm{~d} / \mathrm{d}$ 'da sabit, farklı oranlarda (M0, M5, M10, M20 ve M50) yakıtlar kullanılarak, egzoz emisyonları ve motor performans üzerindeki etkisi incelenmiştir. Deneyler motorun silindir kapağının taşlanmasıyla, yanma odası hacmini artırarak ya da azaltarak sıkıştırma oranının değiştirilmesiyle yapılmıştır.

Deney sonuçlarına göre, karışımdaki metanol oranı arttıkça özgül yakıt tüketimi ve HC, CO emisyon değerleri artarken, efektif verim, $\mathrm{NO}_{\mathrm{x}}$ ve $\mathrm{CO}_{2}$ emisyon değerlerinde azalma görülmüşsür. Sıkıştırma oranı arttıkça da efektif verim, ve $\mathrm{NO}_{\mathrm{x}}$ emisyonu artarken, özgül yakıt tüketimi ve $\mathrm{HC}, \mathrm{CO}_{2}, \mathrm{CO}$ emisyon değerleri azalmıştır. Bu sonuçları oluşturan etkiler ise sırasıyla;

1- ÖYT, metanolün içeriğinde oksijen bulundurması sonucunda 1sıl değerinin daha düşük olması nedeniyle artmıştır.

2- Efektif verim, özgül yakıt tüketimi ile ters oranda gerçekleşeceğinden karışımdaki metanol oranı arttıkça efektif verim azalmış, sıkıştırma oranı arttıkça efektif verim artmıştır.

3- $\mathrm{NO}_{x}$ emisyonu, karışımdaki metanolün adyabatik alev sıcaklığının düşük olması sebebiyle karışım içerisindeki metanol oranının artmasıyla $\mathrm{NO}_{\mathrm{x}}$ miktarı azalmıştır.

4- HC emisyonu, karışımdaki metanol içerisinde karbon miktarının düşük olması ve yanma kalitesinin iyileşmesinden dolayı azalmıştır.

5- CO emisyonu, metanol-benzin karışımındaki metanolün daha az karbon ve yapısında oksijen bulundurması sonucu azalmıştır

Alternatif yakıtlara olan ihtiyaç günden güne artmaktadır. Metanol bitkisel kökenli yakıtlardan elde edilmesiyle ve Türkiye'nin de bir tarım ülkesi olması sebebiyle oldukça önemlidir. Başta ABD olmak üzere diğer ülkeler metanol üretimini destekleyerek, dış ülkelere yaptıkları ihracat ile ülke ekonomisini önemli bir gelir kaynağı oluşturmaktadır. Ülkemizde de metanol üretiminin ülke çıkarları açısından, devlet tarafından desteklenmesi gerektiğini düşünmekteyiz.

Teşekkür: Bu çalışma Marmara Üniversitesi, Bilimsel Araştırma Projeleri Koordinasyon Biriminin (BAPKO) FEN-C-YLP 191212-0353 (Proje Adı: Alkol Benzin Karışımlarında Çalışma Parametrelerinin Performans ve Emisyonlara Etkisinin İncelenmesi) numaralı projesi ile desteklenmiştir.

\section{KAYNAKLAR}

[1] İçingür, Y., Yamık, H., (2003). Metil ve Etil Esterlerin Dizel Yakıtı Olarak Kullanılma İmkanlarının Deneysel Olarak Araştırılması. Politeknik Dergisi, 459-464.

[2] Yüksel, F., Yüksel, B. (2004). The Use of Ethanol-Gasoline Blend as a Fuel in an SI Engine. Renewable Energy, 29, 1181-1191.

[3] Bayraktar, H. (2005). Experimental and Theoretical İnvestigation of Using Gasoline-Ethanol Blends in Spark-İgnition Engines. Renewable Energy, 30, 1733-1747.

[4] Abu-Zaid, M., Badran, O., Yamin, J., (2004). Effect of Methanol Addition on the Performance of Spark Ignition Engines. Energy Fuels, 312-315.

[5] Al-Dawood, A.M. (1998). Effect of Blending MTBE, Methanol, or Ethanol with Gasoline on Performance and Exhaust Emissions of SI engines, Master of Science in Mechanical Engineering, King Fahd University of Petroleum\&Minerals, Dhahran, SAUDI ARABIA, UMI Number: 1398014. 
[6] Bilgin, A., Sezer, İ., (2008). Effects of Methanol Addition to Gasoline Performance and Fuel Cost of a Spark Ignition Engine. Karadeniz Technical University, Trabzon, Turkey, Energy Fuels, 22 (4), 2782-2788.

[7] Çanakçı, M., Özsezen, A.N., Alptekin, E., Eyidoğan, M. (2012). Impact of Alcohol-Gasoline Fuel Blends on the Exhaust Emission of an SI. Renewable Energy 52, 111-117.

[8] Borat, O., Sürmen, A., Balc1, M. (1992). İçten Yanmalı Motorlar, Gazi Üniversitesi Teknik Eğitim Fakültesi vakfı yayınları, Ankara.

[9] Sayın, C., Çanakçı, M., Kılıçaslan, İ., Özsezen, N. (2005). Çift Yakıt (Benzin+LPG) Kullanımının Motor Performansı ve Emisyonlar Üzerine Etkisinin Deneysel Analizi. Gazi Üniversitesi Mühendislik Mimarlık Fakültesi Dergisi, Cilt 20, Sayi 4, 483-491.

[10] Richard, L., Bechtold P.E. (1997). Alternative Fuels Guidebook. Society of Automotive Engineers, Inc. Warrendale, PA, USA.

[11] Salman, M.S. (1996) Buji Ateşlemeli Motorlarda Yanma Hızının Performansa Etkileri, Doktora Tezi, Gazi Üniversitesi Fen Bilimleri Enstitüsü, Ankara, Türkiye.

[12] Wu, C.W., Chen R.H., Pu, J.Y., Lin, T.H., (2004). The Influence of Air-Fuel Ratio on Engine Performance and Pollutant Emission of An SI Engine Using Ethanol-Gasoline Blended Fuels. Atmospheric Environment, 38 (40 SPEC.ISS.), 7093-7100.

[13] Kodah, Z., Soliman, S. (2000) Combustion in a Spark Ignition Engine. Applied Energy, 66. 237-250.

[14] Soruşbay, C. (1999) İçten Yanmalı Motorlarda Egzoz Gazları Emisyonları. İTU Makine Fakültesi Ders Notları, İstanbul.

[15] Heywood, J.B. (1988). Internal Combustion Engine Fundamentals, McGraw-Hill Book Co., USA.

[16] Ergeneman, M., Kutlar, A., Mutlu, M., Arslan, H. (1998) Taşıt Egzozundan Kaynaklanan Kirleticiler, Birsen Yayınevi, İstanbul, Türkiye.

[17] Ajav, E.A., Akingbehin, O.A. (2002). A Studey of Some Fuel Properties of Local Ethanol Blended with Diesl Fuel. Ibadan University Technology Faculty, Nijerya.

[18] Eyidoğan, M. (2008). Etanol-Benzin ve Metanol-Benzin Karışımlarının Buji Ateşlemeli Bir Motorun Yanma Karakteristiği ve Egzoz Emisyonlarına Etkisinin İncelenmesi. Yüksek Lisans Tezi, Kocaeli Üniversitesi Fen Bilimleri Enstitüsü, Kocaeli, Türkiye, 26-27. 